\title{
Surgery for simple and complex subaortic stenosis in children and young adults: Results from a prospective, procedure-based national database
}

\author{
Dan M. Dorobantu, MBBS, ${ }^{a}$ Mansour T. Sharabiani, PhD, ${ }^{\mathrm{b}}$ Robin P. Martin, FRCP, ${ }^{\mathrm{a}}$ \\ Gianni D. Angelini, FRCS, ${ }^{\mathrm{a}, \mathrm{b}}$ Andrew J. Parry, FRCS, ${ }^{\mathrm{a}}$ Massimo Caputo, MD, ${ }^{\mathrm{a}, \mathrm{c}}$ and \\ Serban C. Stoica, FRCS ${ }^{\mathrm{a}}$
}

Objective: To identify the outcomes of surgically treated subaortic stenosis in a national population.

\begin{abstract}
Methods: From 2000 to 2013, 1047 patients aged < 40 years underwent 1142 subaortic stenosis procedures. Of the 1047 patients, $484(46.2 \%)$ were considered to have complex stenosis (CS) because at or before the first operation they had mitral valve (MV) disease, aortic valve disease, aortic coarctation or an interrupted aortic arch.
\end{abstract}

Results: The 30 -day mortality was $0.7 \%$ for simple stenosis (SS), $2.3 \%$ for CS $(P=.06)$, and $1.6 \%$ overall. Age $<1$ year $(P<.01)$, MV procedure $(P=.02)$ and an interrupted aortic arch at the index procedure $(P<.01)$ were risk factors for early death. Konno-type procedure early mortality was $2.4 \%$. The 12 -year survival was $97.1 \%$, with a significant difference between SS and CS (hazard ratio [HR], 4.53; $P=.02$ ). Having MV disease alone (HR, 4.11; $P=.02$ ), MV disease plus aortic coarctation (HR, 6.73; $P=.008$ ), and age $<1$ year (HR, 6.72; $P<.001$ ) were risk factors for late mortality. Freedom from subaortic reintervention overall was $92.3 \%$ and $88.5 \%$ at 5 and 12 years, respectively, much greater with CS than with SS (HR, 4.91; $P<.0001$ ). The independent risk factors for reintervention were younger age at the index procedure (HR, $0.1 / \mathrm{y} ; P=.002)$, concomitant MV procedure (HR, 2.68; $P=.019)$, ventricular septal defect plus interrupted aortic arch (HR, 3.19; $P=.014)$, and ventricular septal defect plus aortic coarctation (HR, 2.41; $P=.023$ ). Undergoing a concomitant aortic valve procedure at the index procedure was protective (HR, $0.29 ; P=.025)$.

Conclusions: Patients with SS had excellent outcomes. However, those with CS had worse long-term survival and freedom from reintervention, with morbidity and mortality greatest in young patients with multiple lesions. Additional evaluation in large-scale prospective studies is warranted. ( $\mathrm{J}$ Thorac Cardiovasc Surg 2014;148:2618-26)

Subaortic stenosis (SAS) is a polymorphic condition. Anatomically, it can range from an isolated discrete stenosis to complex forms of left ventricular (LV) outflow tract obstruction. Other anatomic associations have been well described, including septal malalignment and multilevel obstruction. Not all defects will be present simultaneously;

From the University Hospitals Bristol National Health Services Trust, ${ }^{\mathrm{a}}$ Bristol, United Kingdom; Imperial College, ${ }^{\mathrm{b}}$ London, United Kingdom; and Rush University Medical Center, ${ }^{\mathrm{c}}$ Chicago, Ill.

This research was supported by the National Institute for Health Research Bristol Cardiovascular Biomedical Research Unit.

Disclosures: Robin P. Martin reports lecture fees from Medtronic. All other authors have nothing to disclose with regard to commercial support.

Read at the 94th Annual Meeting of The American Association for Thoracic Surgery, Toronto, Ontario, Canada, April 26-30, 2014.

The present study reports independent research funded by the National Institute for Health Research. The views expressed are those of the authors and not necessarily those of the National Health Services, National Institute for Health Research, or the Department of Health.

Received for publication April 8, 2014; revisions received May 26, 2014; accepted for publication June 27, 2014; available ahead of print Aug 22, 2014.

Address for reprints: Serban C. Stoica, FRCS, Department of Paediatric Cardiac Surgery, Bristol Children's Hospital, University Hospitals Bristol, Upper Maudlin St, Bristol BS2 8BJ, United Kingdom (E-mail: serban.stoica@uhbristol.nhs.uk).

0022-5223/\$36.00

Copyright (c) 2014 by The American Association for Thoracic Surgery

http://dx.doi.org/10.1016/j.jtcvs.2014.06.091 some adjacent lesions, such as aortic valve (AV) disease, evolve after primary treatment of SAS. Surgical treatment is generally successful; however, a risk of recurrence exists, which has been reported at $7.2 \%$ to $27 \% .{ }^{1-6}$ Many factors influence the long-term outcomes, including patient age and size, preoperative gradient, surgery timing, performance of myectomy, and anatomic complexity. Single-institution studies have been restricted by patient numbers, and multicenter studies are better placed to offer more insight.

In the United Kingdom, the Central Cardiac Audit Database (CCAD), hosted by the National Institute for Cardiovascular Outcomes Research, has collected data from congenital UK centers from 2000 onward. It captures all pediatric cardiac surgical and catheter procedures and all adult congenital cardiac procedures (defined as those performed for a cardiac defect present from birth). The audit database has limited clinical information; nevertheless, through complete procedure coverage and linkage with survival statistics, it has provided a unique opportunity to examine the outcomes of all patients undergoing certain procedures.

The objectives of the present SAS study were to (1) describe the early- and long-term survival and freedom from reintervention in a national population of consecutive, 


$$
\begin{aligned}
& \text { Abbreviations and Acronyms } \\
& \begin{aligned}
\text { AV } & =\text { aortic valve } \\
\text { AVR } & =\text { AV replacement } \\
\text { CCAD } & =\text { Central Cardiac Audit Database } \\
\text { CI } & =\text { confidence interval } \\
\text { CoA } & =\text { aortic coarctation } \\
\text { CS } & =\text { complex stenosis } \\
\text { HR } & =\text { hazard ratio } \\
\text { IAA } & =\text { interrupted aortic arch } \\
\text { LV } & =\text { left ventricular } \\
\text { MV } & =\text { mitral valve } \\
\text { SAS } & =\text { subaortic stenosis } \\
\text { SS } & \text { simple stenosis } \\
\text { VSD } & =\text { ventricular septal defect }
\end{aligned}
\end{aligned}
$$

unselected cases; (2) examine how the outcomes of simple stenosis (SS) and complex stenosis (CS), further defined in subsequent section, differ; and (3) describe the influence of $\mathrm{AV}$ procedures such as AV replacement (AVR), Ross, and Konno. The results are presented in aggregate for the cohort and for the various subgroups.

\section{METHODS}

\section{Data Set}

The National Institute for Cardiovascular Outcomes Research brings together analysts and clinicians with the aim of providing data about surgical and catheter-based heart procedures and outcomes. The results are obtained by collecting key validated data from all UK heart units into cardiovascular registries (available at: https://nicor4.nicor.org.uk/). The National Institute for Cardiovascular Outcomes Research mechanism for congenital data capture, cleaning, and validation is similar to that adopted for adult cardiac surgery. ${ }^{7}$ Using linkage with census records at the Office of National Statistics, the audit reports survival at 30 days and 1 year after the index procedure. Distilled information from the core database is reported online. The data represent a "real world" picture. CCAD data are actively audited, both internally and externally. About $15 \%$ of the patients will have no follow-up data beyond their hospital stay, because linkage with survival registries of Northern Ireland and Scotland cannot be done consistently with a National Health Services number, $5 \%$ will be foreign patients, and the remainder will have social data errors.

The indications for the primary subaortic (index) procedure and subsequent reinterventions were provided by multidisciplinary groups at each center. The submitted procedure codes are those recorded in each center's logs and are audited regularly. The additional diagnoses were those selected by the reporting clinicians; the concordance between the procedure performed and the diagnosis reported was also audited, with the overall key data quality index $>95 \%$.

Recruitment into the study continued until April 2012, when the last set of validated data was available. The data were anonymized, and the need for patient-level consent was waived by the CCAD research board. The procedures performed for degenerative causes associated with hereditary conditions (eg, Marfan syndrome) were not considered congenital. Coexisting complex heart abnormalities were excluded (ie, univentricular conditions, valvular atresia, atrioventricular septal defect, transposition of the great arteries, common arterial trunk, Fallot and Fallot-type defects, severe vascular abnormalities [eg, major aortopulmonary collaterals], or isomerism). Patients with aortic coarctation ( $\mathrm{CoA})$ and interrupted aortic arch (IAA) were included owing to the clinical significance in the context of multilevel left-sided obstruction. The patients were considered to have SS or CS according to the definitions listed in Table 1. Of the 1047 patients, 58 had MV or AV abnormalities noted during follow-up (but not before the index procedure) that led to uncertainty regarding the initial diagnosis of the pathologic entity. We believe that, in principle, they satisfied the conditions of CS; however, having incomplete diagnosis and clinical history data, we preferred that such patients remain unassigned to either group (but their data were still included in the aggregate analysis because of valid survival data). All tests involving comparisons between CS and SS were performed initially including these patients in the CS group and then excluding them, with insignificant differences in the results. Thus, the reported results are from the analyses without such patients. Because of the usage of 2 ambiguous procedure codes (ie, 120822 [subaortic obstruction relief] and 120713 [LV outflow tract obstruction relief]), it was not possible to determine the proportion of patients with myectomy.

\section{Statistical Analysis}

The frequencies are given as the absolute numbers and percentages, continuous values as the mean \pm standard deviation, or median and interquartile range. Short-term mortality was calculated per procedure, reported according to the discharge status and 30-day life status (where available). The estimates of long-term survival were made using the Kaplan-Meier method, with all-cause mortality as the failure event. Freedom from reintervention was estimated using the Kaplan-Meier method and a competing risks method ("stcompet" routine for STATA; StataCorp, College Station, Tex) using reintervention and death as competing events. The predictor variables for short-term mortality were determined using the Fisher exact test or logistical regression analysis. For long-term survival and freedom from reintervention, we performed univariable analysis using the variables listed below. To identify independent risk factors, we used a multivariable Cox proportional hazards regression model and a competing risks regression model $^{8}$ (1 variable/10 events) with stepwise forward selection and backward elimination (with significant variables from univariable analysis, $P<.1$ ). Age (continuous) and categorical ( $<1$ and $>1$ year), sex, concomitant procedures (mitral valve [MV] or AV procedures, ventricular septal defect [VSD] closure, CoA repair), other abnormalities present at the index surgery (MV, AV, CoA, VSD, or associations such as VSD + CoA, $\mathrm{MV}+\mathrm{CoA}$, and VSD+IAA), Konno-type procedure, and genetic disorders were examined. The results from the Cox and competing risks regression analyses were similar; thus, we chose to report only the hazard ratio (HR) and not the sub-HRs for practical reasons. Complex versus simple SAS comparisons were performed separately, independent of the multivariable model. Stratification by center was used, as appropriate. Adjusted HRs are given when bivariable or multivariable models were used. The proportional hazard assumption was tested visually and also using Schoenfeld residuals. The population characteristics were compared using the MannWhitney $U$ test, $t$ test, and chi-square test. Statistical analyses were performed using STATA/IC, version11.2 (StataCorp LP).

\section{RESULTS}

A total of 1673 patients with a SAS relief procedure performed from April 1, 2000 to March 31, 2012 were analyzed initially. Those with complex heart abnormalities $(n=456)$, age $>40$ years $(n=77)$, hypertrophic cardiomyopathy $(\mathrm{n}=37)$, transcatheter approach $(\mathrm{n}=15)$, unknown age at the index procedure $(n=41)$ were eliminated, resulting in a final group of 1047 patients. The completeness of the data is presented in Table 2.

These 1047 patients underwent 1142 subaortic relief procedures, with 82 a Konno-type operation (including 
TABLE 1. Definitions of terms

SAS reintervention

AV reintervention

Complex SAS

Simple SAS

Associated AV pathology

Associated MV pathology

Associated VSD, CoA, IAA

Genetic syndrome
Any reoperation or catheter-based procedure related to relief of subaortic valve region obstruction

Reoperation or catheter-based procedure related to AV apparatus (including valvuloplasty/valvotomy and AVR of any type with or without root replacement)

SAS with $\geq 1$ of the following associated diagnoses: AV or MV pathology, CoA, IAA, or tunnel stenosis requiring a Konno operation

SAS associated with, at most, isolated VSD, pulmonary or tricuspid valve abnormalities, or other miscellaneous minor defects

The existence of an AV abnormality, stenosis, or regurgitation before the index operation (not including bicuspid valve with no hemodynamic effect)

The existence of a MV abnormality, stenosis, or regurgitation at or before the index operation

Documented VSD, CoA, or IAA at any point during patient follow-up, corrected or not

Documented genetic disease at any point (Marfan, Noonan, DiGeorge, Down, Turner, Edwards, and Williams syndromes or nonclassified chromosomal abnormalities)

First SAS relief procedure captured in database

Index operation

alve; $A V R$, aortic valve replacement; $M V$, mitral valve; $C O A$, coarctation or hypoplasia of the aorta; $I A A$, interrupted aortic arch; $V S D$, ven$S A S$, Subaortic stenosis;
tricular septal defect.

modified Konno, Konno-Rastan, and Ross-Konno). The patient characteristics are listed in Table 3, and the neonatal group is described in detail in Table 4. The CS group had longer bypass, crossclamp, and circulatory arrest times and a longer hospital stay than did the SS group $(P<.0001)$ and were younger, smaller, and had a shorter follow-up period $(P<.01)$. Data related to the associated abnormalities and concomitant procedures for the CS group $(\mathrm{n}=484)$ are listed in Table 5. Of the 505 patients with SS, $21(4.2 \%)$ had a genetic disorder, $116(23.0 \%)$ a VSD, and $97(19.2 \%)$ VSD repair. A total of 140 patients (13.4\%) had had myectomy reported; however, because of the ambiguous coding, we believed the number was an underestimate. Thus, we did not examine the influence of myectomy.

\section{Early Mortality}

Hospital mortality was $1.24 \%$ overall $(0.6 \%$ for SS, $1.9 \%$ for CS). The short-term mortality (at 30 days) was $1.6 \%$ overall, $0.7 \%$ for SS, and $2.3 \%$ for CS $(P=.057)$. On bivariable analysis, the risk factors for short-term mortality were a MV procedure at the index operation $(5.63 \%$ vs $1.30 \% ; P=.02)$, age $<1$ year $(9.4 \%$ vs $0.8 \%$;

TABLE 2. Data completeness

\begin{tabular}{lc}
\hline \multicolumn{1}{c}{ Variable } & Data complete $(\%)$ \\
\hline NHS number ID & 83.57 \\
Diagnosis & 96.75 \\
Patient weight & 95.03 \\
Sternotomy number & 73.73 \\
Bypass time & 76.22 \\
Crossclamp time & 76.41 \\
Arrest time & 93.31 \\
Hospitalization period & 97.90 \\
Discharge status & 99.90 \\
30-d life status & 85.96 \\
Follow-up life status & 85.67 \\
\hline
\end{tabular}

NHS, National Health System.
$P<.001)$ and an IAA at the index procedure $(7.8 \%$ vs $1.3 \% ; P=.007)$. A total of 40 patients in the CS group had an IAA, with two thirds of the early deaths among them occurring after IAA surgery at the index procedure. Previously repaired IAA was not a risk factor. Eighty-two Konno-type procedures were performed, with $2.4 \%$ early mortality (vs $1.5 \%$ for non-Konno; $P=.4$ ). Other risk factors were initially identified on univariable analysis (VSD defect or CoA procedure at the index procedure). However, on bivariable analysis, it was concluded that age $<1$ year was a confounder and strongest predictor.

\section{Long-Term Survival and Freedom From Reintervention}

The Kaplan-Meier estimates are listed in Table 6. A significant difference was found in long-term mortality between the 2 groups, with patients with CS more at risk (HR, 4.53; 95\% confidence interval [CI], 1.27-16.11; $P=.02$, adjusted by age). The independent risk factors for long-term mortality were age $<1$ year (HR, 6.72; $95 \% \mathrm{CI}, 2.37-18.98, P<.001)$, having an MV abnormality (HR, 4.11; 95\% CI, 1.21-13.92; $P=.02$ ). Having MV disease plus CoA resulted in an even greater risk (HR, 6.73; 95\% CI, 1.64-27.59; $P=.008$ ), although CoA alone was not a risk factor.

In terms of freedom from subaortic reintervention, a very significant difference was found between the SS and CS groups (Figure 1). Examining the data in aggregate, the independent risk factors for reintervention were younger age at the index procedure (HR, 0.1/y, 95\% CI, 1.03-1.17; $P=.002$ ), a concomitant MV procedure (HR, 2.68; $95 \%$ CI, $1.17-6.09 ; P=.019)$, VSD + CoA $(\mathrm{HR}, 2.41 ; 95 \% \mathrm{CI}$, $1.12-5.14 ; P=.023)$, and VSD+IAA (HR, 3.19; 95\% CI, $1.26-8.04 ; P=.014)$. Of the 9 patients with VSD+IAA who required a SAS reintervention, 6 underwent repair for residual $\mathrm{CoA}$ at the index procedure compared with 
TABLE 3. Patient- and procedure-related data

\begin{tabular}{|c|c|c|c|c|}
\hline Variable & Total* & Simple SAS & Complex SAS & $P$ value \\
\hline Patients & 1047 (100) & $505(48.2)$ & $484(46.2)$ & \\
\hline Age (y) & $6.5(2.7-12.2)$ & $6.8(3.5-12)$ & $5.7(2-12.4)$ & .008 \\
\hline \multicolumn{5}{|l|}{ Sex } \\
\hline Male & $644(61.5)$ & $311(61.6)$ & $300(62.0)$ & .87 \\
\hline Female & $403(38.5)$ & $194(38.4)$ & $184(38.0)$ & .87 \\
\hline \multicolumn{5}{|l|}{ Age group } \\
\hline Neonate $(<30 \mathrm{~d})$ & $19(1.8)$ & $2(0.4)$ & $17(3.5)$ & $<.001$ \\
\hline Infant (1-12 mo) & $80(7.6)$ & $26(5.1)$ & $53(11.0)$ & $<.001$ \\
\hline Child (1-16 y) & $804(76.8)$ & $421(83.4)$ & $338(69.8)$ & $<.001$ \\
\hline Young adult (16-40 y) & $144(13.8)$ & $56(11.1)$ & $76(15.7)$ & .05 \\
\hline \multicolumn{5}{|l|}{ Follow-up (y) } \\
\hline Mean \pm SD & $5.5 \pm 3.9$ & $5.9 \pm 4.1$ & $4.8 \pm 3.5$ & $<.001$ \\
\hline Median (IQR) & $5.3(2.2-8.9)$ & $6.0(2.5-9.7)$ & $4.4(1.9-7.5)$ & $<.001$ \\
\hline Bypass time (min) & $61(45-88)$ & $74(51-112)$ & $54(40-70)$ & $<.001$ \\
\hline Crossclamp time (min) & $37(26-55)$ & $32(24-45)$ & $45(32-75)$ & $<.001$ \\
\hline Circulatory arrest & $44(4.5)$ & $7(1.4)$ & $35(7.2)$ & $<.001$ \\
\hline Circulatory arrest time (min) & $20(9-30)$ & $24(3-36)$ & $16(9-29)$ & .61 \\
\hline Hospital stay (d) & $5(4-7)$ & $5(4-6)$ & $6(5-9)$ & $<.001$ \\
\hline
\end{tabular}

Data presented as n (\%), median (IQR), or mean \pm SD. SAS, Subaortic stenosis; $S D$, standard deviation; IQR, interquartile range. *A total of 58 patients $(5.6 \%)$ were not classifiable as simple or complex but were included in the total.

only 2 of the 12 with VSD+CoA. Undergoing a concomitant AV procedure was found to be protective (HR, 0.29; $95 \% \mathrm{CI}, 0.10-0.85 ; P=.025)$. When late outcomes were examined at different age intervals, all subgroups $>1$ year old had comparable mortality results, better than those of the 0 - to 1-year cohort. In contrast, in the reintervention group, a trend was found, with patients aged 0 to 10 years most at risk (Figure 2). Competing risks analysis showed that at 12 years, $85.8 \%$ of the patients were alive with no reoperation, $3 \%$ had died without a reoperation, and $11.2 \%$ had undergone a reoperation. Also, the differences in reintervention risk in the presence of death as a competing event between the SS and CS forms were greater for younger patients and less so for older ones (Figure 1, $B$ ). In young adult patients, the results were excellent, and no differences could be demonstrated.

\section{Other Subgroup Analyses}

AV disease. We considered the outcomes separately for the subgroup of patients with documented AV pathologic features at index $(\mathrm{n}=296)$, with a mean age of 10.3 years. Of these, $121(40.9 \%)$ had stenosis, $94(31.8 \%)$ had regurgitation, $12(4 \%)$ had mixed disease, and $69(23.3 \%)$ had a nonclassified abnormality. The AV procedure at the index operation was none in $114(38.5 \%)$, surgical valvuloplasty in $59(20 \%)$, AV replacement (AVR) in $108(36.5 \%)$, and an unclassified procedure in $15(5 \%)$. The AVR type was a Ross (or Ross-Konno) operation in 63, a mechanical prosthesis AVR (including root replacement or Bentall) in 21, an unknown AVR type in 21, and bioprosthesis and homograft in 1 each. Long-term mortality and reinterventionsmoothed hazard plots for these patients are shown in
Figure 3. Younger age was a risk factor for AV/SAS reintervention (HR, $0.12 / y, 95 \%$ CI, 0.83-0.94; $P<.001$ ) but undergoing an AVR procedure at index was protective (naturally for aortic reintervention, but also for SAS reintervention, $P<.001$; no such event was observed in the AVR group, regardless of AVR type). The reoperations performed in this subgroup are summarized in Table 7.

Konno procedure. Finally, we analyzed the subgroup of 82 patients who had undergone a Konno-type procedure, studying the clinical and outcomes data (Table 8). Two early deaths occurred, with 6 deaths during the total follow-up period (median, 3.3 years), all in the Ross-Konno group. In terms of reintervention, 3 early events occurred (a Ross-Konno and an AVR after modified Konno and AV valvuloplasty after Ross-Konno that also resulted in the patient's death at 18 days old) and 2 late events occurred (a redo modified Konno and an AV valvuloplasty), resulting in the estimates listed in Table 9.

\section{DISCUSSION}

We found that SAS relief can be performed with very good results; however, the mortality and morbidity were greatest in young patients with multiple abnormalities. This is, to our knowledge, the largest observational multicenter study reporting the surgical outcomes for SAS in children and young adults. Furthermore, consecutive patients who had undergone surgery for this condition in the United Kingdom for $>1$ decade were analyzed. Although the clinical detail was scant, the assumption was that the local multidisciplinary groups considered all patient factors and surgical preference in recommending a certain procedure and its timing. The echocardiographic details were 
TABLE 4. Neonatal subaortic stenosis relief group—clinical data, procedures, and outcomes summary

\begin{tabular}{|c|c|c|c|c|}
\hline $\begin{array}{l}\text { Patient age }(d) \text {; } \\
\text { weight }(\mathbf{k g})\end{array}$ & Additional diagnoses & Index procedure & Other procedures (age; y) & Life status \\
\hline $1 ; 2.8$ & Aorto-LV tunnel & $\begin{array}{l}\text { SAS relief, PDA closure, ECMO } \\
\text { needed }\end{array}$ & None & $\begin{array}{l}\text { Died in hospital (day } 39 \\
\text { postoperatively) }\end{array}$ \\
\hline $4 ; 4$ & CoA, ASD, VSD & $\begin{array}{l}\text { SAS relief, CoA repair, ASD and } \\
\text { VSD closure }\end{array}$ & NA & Alive at $3.6 \mathrm{y}$ \\
\hline $4 ; 2.5$ & VSD, AV disease & $\begin{array}{l}\text { SAS relief, Bentall operation, VSD } \\
\text { closure }\end{array}$ & NA & $\begin{array}{l}\text { Alive at discharge }(9 \mathrm{~d}) \\
\text { lost to follow-up }\end{array}$ \\
\hline $5 ; 3.5$ & IAA, VSD & SAS relief, IAA repair, VSD closure & None & $\begin{array}{l}\text { Died in hospital (day } 27 \\
\text { postoperatively) }\end{array}$ \\
\hline $6 ; 3$ & IAA, VSD & SAS relief + IAA repair, VSD closure & SAS relief (1 y) & Died at $5.5 \mathrm{y}$ \\
\hline $6 ; 2.9$ & CoA, VSD, AV stenosis & CoA repair, VSD closure & $\begin{array}{l}\text { BAV }(4 \mathrm{mo}) \\
\text { Ross+SAS relief }(8 \mathrm{mo})\end{array}$ & $\begin{array}{l}\text { Died in hospital (day } 4 \\
\text { after Ross) }\end{array}$ \\
\hline $7 ; 4$ & AV stenosis, ALCAPA & $\begin{array}{l}\text { Ross-Konno operation, ALCAPA } \\
\text { repair }\end{array}$ & $\begin{array}{l}\text { Unknown procedure }(5.4 \mathrm{y}) \\
\text { RVOT procedure }(5.6 \mathrm{y})\end{array}$ & Alive at $8.7 \mathrm{y}$ \\
\hline $8 ; 3.5$ & AV stenosis & SAS relief, SAV & NA & Alive at $5.3 \mathrm{y}$ \\
\hline $8 ; 3.1$ & IAA, VSD & SAS relief, IAA repair, VSD closure & $\begin{array}{l}\text { Subaortic shelf resection } \\
\quad(2.5 \mathrm{y})\end{array}$ & Alive at $3.7 \mathrm{y}$ \\
\hline $9 ; 4.2$ & AV stenosis, ASD & $\begin{array}{l}\text { SAS relief, aortic root replacement } \\
\text { (non-Ross), ASD closure }\end{array}$ & $\begin{array}{l}\text { BAV }(3 \mathrm{~d}) \\
\text { Ross procedure }(3 \mathrm{mo})\end{array}$ & Alive at $1.3 \mathrm{y}$ \\
\hline $9 ; 3.6$ & $\begin{array}{l}\text { MV stenosis, AV stenosis, CoA, } \\
\text { VSD, ASD }\end{array}$ & SAS relief, SAV, CoA repair & $\begin{array}{l}\text { Balloon dilatation of re-CoA } \\
\quad(10 \mathrm{mo}) \\
\text { ASD closure }(2.8 \mathrm{y})\end{array}$ & Alive at $6.9 \mathrm{y}$ \\
\hline $9 ; 3.4$ & AV stenosis & Ross-Konno operation & $\operatorname{SAV}(17 \mathrm{~d})$ & $\begin{array}{l}\text { Died in hospital (day } 20 \\
\text { after SAV) }\end{array}$ \\
\hline $10 ; 3.6$ & CoA, VSD & SAS relief, CoA repair, VSD closure & NA & Alive at $1 \mathrm{y}$ \\
\hline $11 ; 3$ & VSD & SAS relief, VSD closure & NA & $\begin{array}{l}\text { Alive at discharge ( } 27 \mathrm{~d}) \\
\text { lost to follow-up }\end{array}$ \\
\hline $11 ; 3.5$ & AV stenosis, CoA, ASD, PDA & $\begin{array}{l}\text { SAS relief, CoA repair, ASD and PDA } \\
\text { closure }\end{array}$ & $\begin{array}{l}\text { SAV }(1.5 \mathrm{y}) \\
\text { Ross-Konno }(4.5 \mathrm{y})\end{array}$ & Alive at $6 \mathrm{y}$ \\
\hline $11 ; 3.8$ & $\mathrm{CoA}$ & SAS relief, CoA repair & None & $\begin{array}{l}\text { Died in hospital (day } 34 \\
\text { postoperatively) }\end{array}$ \\
\hline $12 ; 8.4$ & DiGeorge syndrome, AV stenosis & SAS relief, SAV & BAV $(9$ y) & Alive at $11.3 \mathrm{y}$ \\
\hline $21 ; 3.3$ & $\mathrm{MV}$ regurgitation, $\mathrm{AV}$ stenosis & Ross-Konno operation & $\begin{array}{l}\text { Previous SAV }(2 \mathrm{~d}) \\
\text { MVR }(24 \mathrm{~d}) \\
\text { RVOTO procedure }(1.2 \mathrm{y}) \\
\text { Unknown procedure }(2.2 \mathrm{y})\end{array}$ & $\begin{array}{l}\text { Died } 99 \mathrm{~d} \text { after unknown } \\
\text { procedure }\end{array}$ \\
\hline $21 ; 4$ & AV stenosis, VSD & Ross-Konno operation & NA & Alive at $10.2 \mathrm{y}$ \\
\hline
\end{tabular}

$L V$, Left ventricular; $S A S$, subaortic stenosis; $P D A$, patent arterial duct; $E C M O$, extracorporeal membrane oxygenation; $C o A$, coarctation of the aorta; $A S D$, atrial septal defect; $V S D$, ventricular septal defect; $N A$, not available; $A V$, aortic valve; $I A A$, interrupted aortic arch; $B A V$, balloon aortic valvulotomy; $A L C A P A$, anomalous left coronary artery from the pulmonary artery; $R V O T$, right ventricular outflow tract; $S A V$, surgical aortic valvulotomy; $M V$, mitral valve; $M V R$, mitral valve replacement; RVOTO, RVOT obstruction.

not available; however, we gathered enough good-quality outcomes data. We lacked data on the incidence and prevalence of LV outflow tract obstruction at birth, because the CCAD is a procedure-based audit; however, it could be reasonably assumed that many of the estimates from the Liverpool study performed from 1960 to 1991 were still valid for the United Kingdom. ${ }^{9}$

\section{Early Mortality}

The overall mortality of $1.6 \%$ compares favorably with some of the best single-center series, taking into account that our UK cohort also included neonates and other consecutive patients undergoing complex surgery. ${ }^{2,4,10}$ It is unsurprising to find age $<1$ year, IAA, and MV surgery as risk factors for hospital death. The association between IAA and SAS can be very vexing and has been, itself, subject to numerous clinical analyses. After reporting an original series with $20 \%$ mortality, Jacobs and colleagues ${ }^{11}$ highlighted a number of technical pitfalls and even recommended a modification of the Norwood principle in selected cases. Regarding the use of RossKonno adding to the early mortality, this is also in line with existing data. In a series comparing Ross and RossKonno in children, Ruzmetov and colleagues ${ }^{12}$ encountered only 3 early deaths in 78 patients $(3.8 \%)$, but all occurred in the Ross-Konno group. It was reassuring to see that in our population, previous IAA repair was not a risk factor for early death outside the index SAS procedure. However, 6 
TABLE 5. Complex SAS group clinical data at index

\begin{tabular}{|c|c|}
\hline Variable & Value \\
\hline Total & $484(100)$ \\
\hline Genetic disorder & $22(4.6)$ \\
\hline \multicolumn{2}{|l|}{ Associated abnormalities } \\
\hline $\mathrm{AV}^{*}$ & $296(61.2)$ \\
\hline $\mathrm{MV} \dagger$ & $105(21.7)$ \\
\hline VSD & $147(30.4)$ \\
\hline CoA or hypoplasia of the aorta & $160(33.1)$ \\
\hline IAA & $40(8.3)$ \\
\hline Tricuspid/pulmonary & $31(6.4)$ \\
\hline \multicolumn{2}{|l|}{ Associated abnormalities (left heart) } \\
\hline One & $253(52.3)$ \\
\hline Two & $195(40.3)$ \\
\hline Three & $31(6.4)$ \\
\hline Four & $3(0.6)$ \\
\hline \multicolumn{2}{|l|}{ Concomitant procedures } \\
\hline AV repair & $62(12.8)$ \\
\hline AVR & $108(22.3)$ \\
\hline MV procedure & $62(12.8)$ \\
\hline VSD correction & $70(14.5)$ \\
\hline CoA or hypoplasia repair & $30(6.2)$ \\
\hline IAA repair & $4(0.8)$ \\
\hline Tricuspid, RVOT, pulmonary & $24(5.0)$ \\
\hline Konno-type operation $\ddagger$ & $59(12.2)$ \\
\hline \multicolumn{2}{|c|}{$\begin{array}{l}\text { Data presented as n (\%). } A V \text {, Aortic valve; } M V \text {, mitral valve; } V S D \text {, ventricular septal } \\
\text { defect; } C O A \text {, coarctation of the aorta; } I A A \text {, interrupted aortic arch; } A V R \text {, AV replace- } \\
\text { ment; } R V O T \text {, right ventricular outflow tract. *Three patients ( }(7.9 \%) \text { had an AV abnor- } \\
\text { mality noted only after the index operation. †Ten patients }(2.1 \%) \text { had an MV } \\
\text { abnormality noted only after the index operation. } \ddagger \text { Included the Ross-Konno, modi- } \\
\text { fied Konno, and Konno-Rastan operations. }\end{array}$} \\
\hline
\end{tabular}

of 11 early deaths $(55 \%)$ occurred in patients $<1$ year old, and age appears to be an important confounding factor. We did not have enough events to determine the contribution of other risk factors such as concomitant CoA repair or the presence of a VSD (corrected or not).

\section{Long-Term Survival and Freedom From Reintervention}

The subdivision into SS and CS really becomes useful when examining the long-term outcomes. Other investigators who divided their pediatric patients into SS and CS groups evidently found worse outcomes for the complex forms. Valeske and colleagues ${ }^{13}$ reported surgical recurrence of $46 \%$ for CS versus $16 \%$ for SS. Hirata and colleagues $^{2}$ showed that the 15-year freedom from reintervention was $90.4 \%$ versus $72.1 \%$ for the simple and complex forms, respectively. These series are not entirely comparable because the patient demographics and definitions of SS and CS varied between publications. Defining "complex" SAS is an arbitrary exercise. In our CS group, we chose to include lesions on the valves above and below and obstructive arch pathologic features (with or without a VSD). We believed that the presence of a simple VSD would be a minor risk factor in the long term, although some series will report "simple" pathology only as discrete stenosis on a largely intact septum. In our SS group 19.2\% of patients underwent VSD repair, comparable to the $14.7 \%$ reported by van der Linde and colleagues ${ }^{14}$ in their adult series. Overall, $26.4 \%$ were documented with a VSD, close to the $32 \%$ reported by Kitchiner and colleagues. ${ }^{15}$ Any such arbitrary classification will be further complicated by the progressive and intertwined nature of these lesions; the reason we chose our subgroups as we did. Coexisting MV disease and CoA suggests these patients belong to the Shone spectrum. Coexisting VSD and arch abnormalities point to the possibility of a deviated septum. ${ }^{15-17} \mathrm{AV}$ disease is known to evolve in tandem with SAS, even after a successful first operation. The recurrence of SAS and the progression of $\mathrm{AV}$ disease have been linked to several factors: timing or gradient at the first repair, ${ }^{1}$ the proximity of SAS to $\mathrm{AV},{ }^{4}$ and persistently abnormal geometry of the LV outflow tract. ${ }^{18}$ Age at the first operation was intimately associated with the long-term outcome in some series, ${ }^{10}$ although others have postulated that young age at the first operation is a surrogate for more severe Shonetype lesions, which inevitably have more aggressive progression, even after initial treatment. ${ }^{4}$ When we split our group into 4 age groups (neonates and infants, young children, older children, and adults), it was also evident that those $<1$ year old had generally worse outcomes but that the other age groups had more or less similar outcomes during the follow-up period. When we further compared the simple and complex forms at different ages, it become apparent that the complex form adds significantly to the

TABLE 6. Survival and freedom from reintervention data for subaortic stenosis repair

\begin{tabular}{lccr}
\hline \multicolumn{1}{c}{ Variable } & Overall & Simple SAS & Complex SAS \\
\hline Patients (procedures) & $1047(1142)$ & $505(531)$ & $484(530)$ \\
Survival (\%) & & & 97.74 \\
$\quad$ 30-d & 98.40 & 99.32 & $96.65(94.28-98.05)$ \\
5-y estimate* & $98.00(96.80-98.75)$ & $99.51(98.07-99.88)$ & $96.12(93.42-97.73)$ \\
$\quad$ 12-y estimate* & $97.12(95.33-98.23)$ & $98.80(95.62-99.67)$ & \\
Freedom from subaortic reintervention (\%) & & & \\
$\quad$ 5-y estimate & $92.33(90.16-94.04)$ & $97.80(95.61-98.90)$ & $88.80(84.76-91.83)$ \\
12-y estimate & $88.50(85.50-90.90)$ & $95.80(92.35-97.70)$ & $83.66(78.45-87.71)$ \\
\hline
\end{tabular}

Data in parentheses are $95 \%$ confidence intervals, unless otherwise noted. SAS, Subaortic stenosis. *Survival estimate was for 30 -days survivors. 


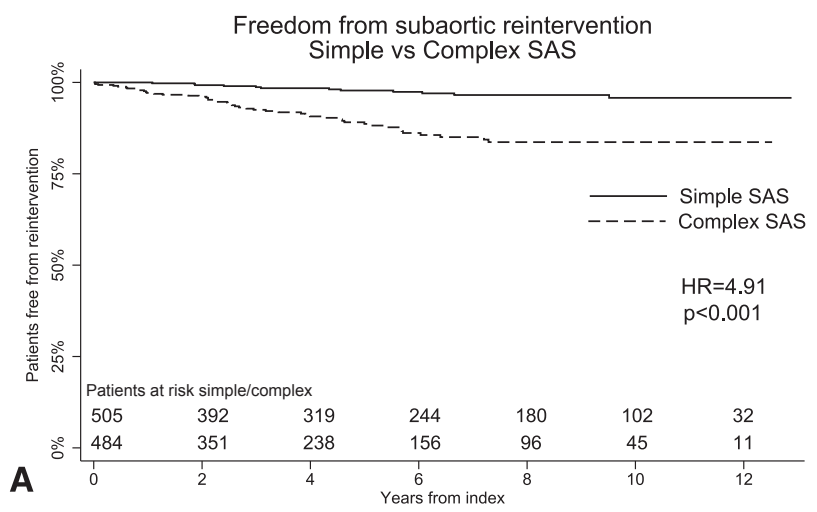

Risk of subaortic reintervention in Simple SAS vs Complex SAS

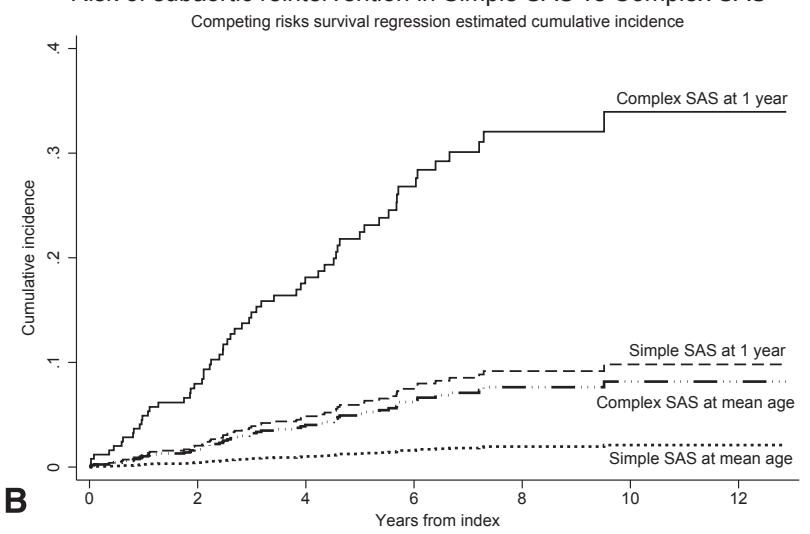

FIGURE 1. A, Kaplan-Meier freedom from subaortic reintervention function comparing simple and complex subaortic stenosis (SAS). B, Comparison of subaortic reoperation risk in simple versus complex SAS showing estimated cumulative incidence function at 1 year of age and mean age (8.7 years), respectively. Competing risks survival regression, adjusted by age, was used, with death as the competing risk. $H R$, Hazard ratio.

reintervention risk at young ages and that this age group is at greater risk of requiring a reoperation even with an isolated lesion (Figures 1, $B$, and 2).

Our results have shown that the actuarial curves for SS and CS do not particularly separate for survival at 12 years (98.8\% vs $96.1 \%)$; however, a significant difference was found in the freedom from reintervention $(95.8 \%$ vs $83.7 \%$; Table 6). The aggregate data suggest that young age at the first operation, Shone-type disease, and coexisting arch abnormalities predispose to early recurrence and mortality. This is in line with the available data; the reports on Shone syndrome have typically been small, single-center series. Although the patients fit the anatomic diagnosis, the intervention can be quite limited. Brown and colleagues ${ }^{19}$ reported that some patients only require as little intervention as CoA repair. In a similar series, St Louis and colleagues $^{20}$ and Delmo Walter and colleagues ${ }^{21}$ noted that treatment of Shone syndrome must be individualized to allow growth of the left ventricular inflow and outflow tracts. We found that the presence of a VSD with either

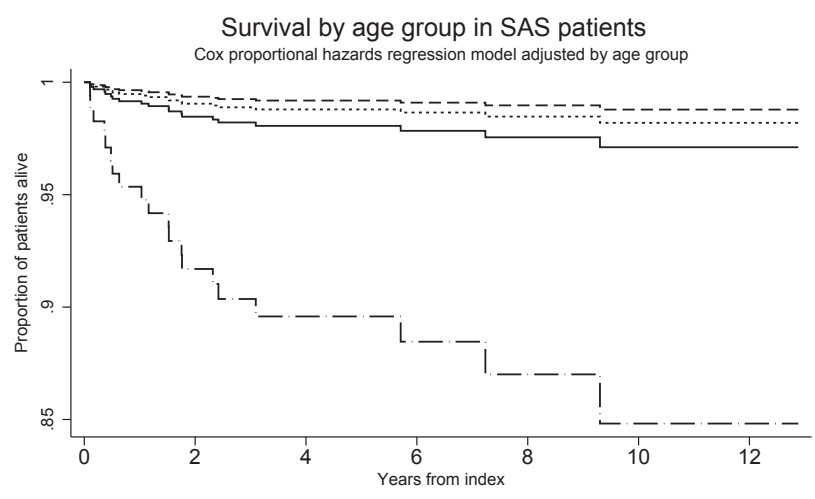

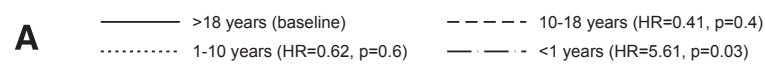

Freedom from subaortic reintervention by age group in SAS patients

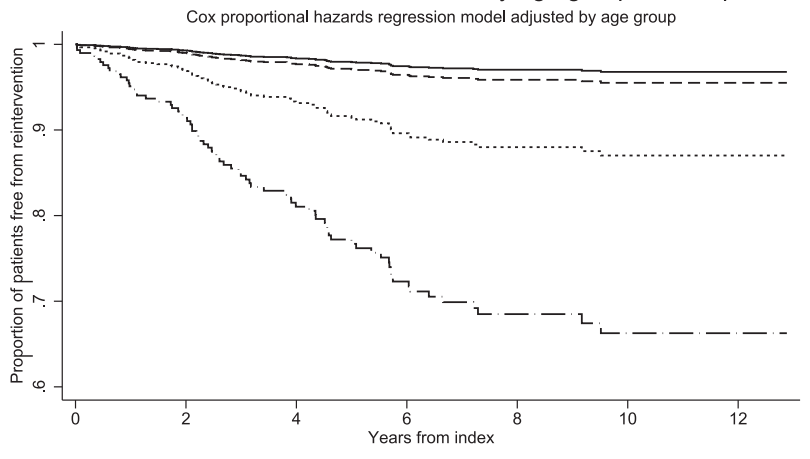

B $>18$ years (baseline) $\quad----10-18$ years $(H R=1.4, p=0.6)$

FIGURE 2. Survivor function plots comparing age groups in terms of long-term risks (Cox regression model adjusted by age group). The vertical axis does not start at 0 . A, Estimated long-term survival with hazard ratios (HRs) stratified by age group. B, Estimated long-term freedom from subaortic reintervention with HRs stratified by age group. SAS, Subaortic stenosis.

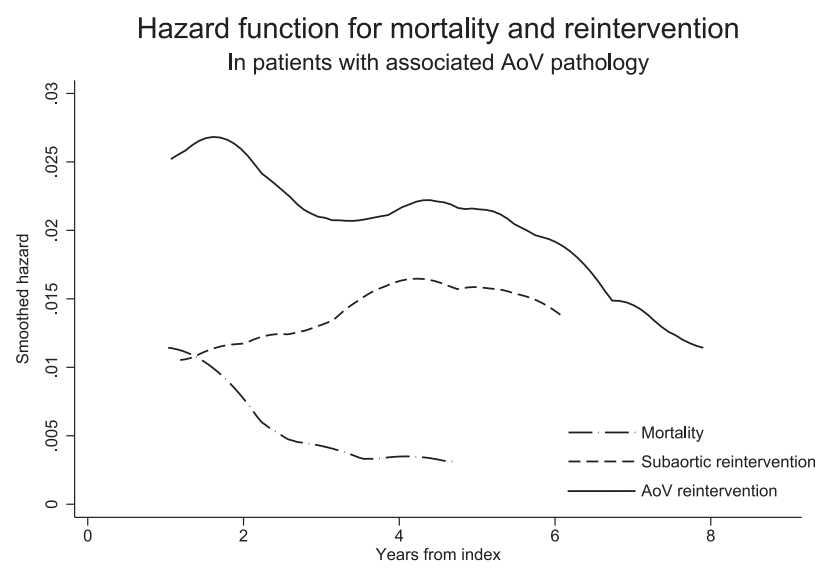

FIGURE 3. Smoothed hazard function plots comparing the risk for different outcomes on the subgroup that presented at the index operation with subaortic stenosis (SAS) and aortic valve ( $A o V)$ pathology. Separate plots were drawn for different failure events: death, AoV reintervention, and SAS reintervention. 
TABLE 7. AV reinterventions in the subgroup with associated AV pathology

\begin{tabular}{lccccc}
\hline & \multicolumn{4}{c}{ Index AV procedure } \\
\cline { 2 - 5 } First AV reintervention & None $(\mathbf{n}=\mathbf{1 1 4})$ & AV repair $(\mathbf{n}=\mathbf{5 9})$ & AVR $(\mathbf{n}=\mathbf{1 0 8})$ & Unknown $(\mathbf{n}=\mathbf{1 5})$ & Total $(\mathbf{n}=\mathbf{2 9 6})$ \\
\hline None* & $94(82.4)$ & $52(88.1)$ & $104(96.3)$ & $14(93.3)$ & $264(89.2)$ \\
AVR & $9(7.9)$ & $5(8.5)$ & $2(1.85)$ & $0(0)$ & $16(5.4)$ \\
Balloon AV valvulotomy & $7(6.2)$ & $1(1.7)$ & $0(0)$ & $0(0)$ & $8(2.7)$ \\
Surgical AV valvulotomy $\dagger$ & $4(3.5)$ & $1(1.7)$ & $2(1.85)$ & $1(6.7)$ & $8(2.7)$ \\
All AV reintervention types & $20(17.6)$ & $7(11.9)$ & $4(3.7)$ & $1(6.7)$ & $32(10.8)$ \\
\hline
\end{tabular}

Data presented as n (\%). Later reinterventions: 5 of 32 patients (16.6\%) underwent a second AV reintervention (2 AVRs, 1 root replacement with valvular resuspension, and 1 redo BAV); 2 of 32 patients (6.25\%) underwent SAS relief reintervention after BAV (1 modified Konno and 1 simple obstruction relief); 1 of 32 patients (3.1\%) underwent a third reoperation (Konno-Rastan after BAV and non-Ross root replacement during the 12-year follow-up period). AV, Aortic valve; $A V R$, AV replacement. *Three patients underwent only SAS relief as their second operation. $\nmid$ Of the 8 patients with surgical AV repair, 4 also underwent concomitant SAS relief.

CoA or an IAA led to greater risk of SAS reintervention, and we could speculate this results from septal malalignment, which was previously linked to younger age at SAS relief but not greater rates of recurrence. ${ }^{15}$ Another interesting finding was that 6 of 9 patients who required SAS reintervention from the VSD+IAA group had previously undergone an arch reintervention (consistent with a previous Congenital Heart Surgeons Society study). ${ }^{22}$ In the VSD + CoA group, only 2 of 12 patients had previously undergone an arch reintervention. This might point to complex relationships among left-sided obstructions, their correction, and relapse.

It is intriguing to note that AVR at the index procedure was protective in our series for the recurrence of SAS. It could be argued that once a valve procedure has been performed, it becomes more difficult to operate by way of the aorta if restenosis occurs, and some patients could be undertreated, or that the AVR improves the exposure of the subaortic area and permits better clearance. However, the data about patients who do not undergo an $\mathrm{AV}$ procedure at index are convincing. When the valve and subaortic membrane are close together, recurrence is more likely and valve stenosis a common occurrence during follow-up after SAS resection. ${ }^{4,23}$ Our results, however, suggest that in practice, these 2 individual lesions can be treated on their own merit and, when AVR is required, this does not negatively affect SAS freedom from reintervention. However, a prospective design would be best suited to study the interactions between AV and SAS pathologic features and determine the best indications for treatment. Overall, it appears that patients have a greater risk of death and AV reintervention early during the follow-up period and a greater risk of SAS reintervention later (Figure 3).

For the Konno-type procedures, we found good longterm results, with $92 \%$ survival at 10 years, comparable to those previously reported. ${ }^{12,24,25}$ However, important variations were present among the studies. As expected, pulmonary and $\mathrm{AV}$ reinterventions were needed in the Ross-Konno patients and SAS relapse after modified Konno required reoperation.

\section{Study Limitations}

The present study was a retrospective study with limited clinical data; however, we had complete procedural coverage of consecutive national patients. The prevalence

TABLE 8. Clinical and demographic data for Konno-type procedures

\begin{tabular}{|c|c|c|c|c|}
\hline Variable & Modified Konno & Ross-Konno & Konno-Rastan & Overall \\
\hline Patients (n) & 14 & 63 & 5 & 82 \\
\hline \multicolumn{5}{|l|}{ Age (y) } \\
\hline Mean \pm SD & $12.6 \pm 11.8$ & $7.7 \pm 8.5$ & $18.1 \pm 12.0$ & $9.2 \pm 9.6$ \\
\hline Median (IQR) & $10.5(2.1-16)$ & $4.5(0.6-12.2)$ & $16.6(8.3-29.4)$ & $7.6(0.9-13.1)$ \\
\hline \multicolumn{5}{|l|}{ Sex } \\
\hline Male & $10(71.4)$ & $45(71.4)$ & $3(60)$ & $58(70.7)$ \\
\hline Female & $4(28.6)$ & $18(28.6)$ & $2(40)$ & $24(29.3)$ \\
\hline \multicolumn{5}{|l|}{ Age group } \\
\hline Neonate $(<30 \mathrm{~d})$ & 0 & $4(6.4)$ & 0 & $4(4.8)$ \\
\hline Infant (1-12 mo) & $1(7.1)$ & $16(25.4)$ & 0 & $17(20.7)$ \\
\hline Child (1-16 y) & $9(64.3)$ & $37(58.7)$ & $2(40)$ & $48(58.6)$ \\
\hline Young adult (16-40 y) & $4(28.6)$ & $6(9.5)$ & $3(60)$ & $13(15.9)$ \\
\hline \multicolumn{5}{|l|}{ Previous procedures } \\
\hline $\mathrm{AV}$ & $2(14.3)$ & $31(49.2)$ & $2(40)$ & $35(42.7)$ \\
\hline SAS repair & $5(35.7)$ & $13(20.6)$ & $1(20)$ & $19(23.2)$ \\
\hline
\end{tabular}

Data presented as mean $\pm \mathrm{SD}$, median (IQR), or n (\%). SD, Standard deviation; $I Q R$, interquartile range; $S A S$, subaortic stenosis; $A V$, aortic valve. 
TABLE 9. Survival and freedom from reintervention for Konno-type procedures

\begin{tabular}{ll}
\hline \multicolumn{1}{c}{ Survival } & \multicolumn{1}{c}{$\%$} \\
\hline 30-d survival & 97.6 \\
10-y survival & $92.50(82.72-96.82)$ \\
10-y freedom from reintervention & \\
Subaortic & $96.55(86.47-99.16)$ \\
Aortic & $92.61(79.35-97.49)$ \\
Pulmonary* & $68.71(49.59-81.81)$ \\
\hline Data in parentheses are $95 \%$ confidence intervals. *Calculated for 63 Ross-Konno \\
patients.
\end{tabular}

of associated abnormalities in this group was comparable to those previously reported in other studies, ${ }^{9,26}$ suggesting that the CCAD guidelines for reporting ${ }^{27}$ are able to generate reliable data. However, information about the sequence of events from the initial diagnosis was limited. This did not allow consideration of the effects of the timing of repairing the associated defects on SAS progression. It also made it difficult to separate the presence of another abnormality from the attempt to correct it at some point as a risk factor (ie, the presence of an associated anomaly correlated with the need for repair). The CCAD reporting of valve lesions and their severity is more discretionary than the need for accurate procedural data. Our report, therefore, was limited in its ability to determine the contribution of associated lesions to SAS progression when these lesions were below the surgical radar. All these issues might ultimately have led to some misclassification for the simple/ complex dichotomization. Also being a procedure-based rather than patient-based audit, a true (diagnosis-centered) prognosis of SAS could not be determined. Finally, we could not analyze the role of myectomy. Also, some patients had incomplete follow-up data (because of geographical reasons; thus, we assumed they did not introduce bias).

\section{CONCLUSIONS}

The present complete coverage national audit of consecutive patients has shown that the contemporary results of SAS surgery are good for both simple and complex subtypes. However, the complex form carries the larger part of the mortality and morbidity burden.

\section{References}

1. Brauner R, Laks H, Drinkwater DC, Shvarts O, Eghbali K, Galindo A. Benefits of early surgical repair in fixed subaortic stenosis. J Am Coll Cardiol. 1997;30: 1835-42.

2. Hirata Y, Chen JM, Quaegebeur JM, Mosca RS. The role of enucleation with or without septal myectomy for discrete subaortic stenosis. J Thorac Cardiovasc Surg. 2009;137:1168-72.

3. Serraf A, Zoghby J, Lacour-Gayet F, Houel R, Belli E, Galletti L, et al. Surgical treatment of subaortic stenosis: a seventeen-year experience. J Thorac Cardiovasc Surg. 1999;117:669-78.

4. Geva A, McMahon CJ, Gauvreau K, Mohammed L, del Nido PJ, Geva T. Risk factors for reoperation after repair of discrete subaortic stenosis in children. $J$ Am Coll Cardiol. 2007;50:1498-504.
5. Stewart JR, Merrill WH, Hammon JW, Graham TP, Bender HW. Reappraisal of localized resection for subvalvar aortic stenosis. Ann Thorac Surg. 1990;50: 197-202; discussion 202-3.

6. Giuffre RM, Ryerson LM, Vanderkooi OG, Leung AKC, Collins-Nakai RL. Surgical outcome following treatment of isolated subaortic obstruction. Adv Ther. 2004;21:322-8

7. Hickey GL, Cosgriff R, Grant SW, Cooper G, Deanfield J, Roxburgh J, et al. A technical review of the United Kingdom National Adult Cardiac Surgery Governance Analysis 2008-11. Eur J Cardiothorac Surg. 2014;45:225-33.

8. Fine J, Grey R. A proportional hazards model for the subdistribution of a competing risk. J Am Stat Assoc. 1999;94:496-509.

9. Kitchiner D, Jackson M, Malaiya N, Walsh K, Peart I, Arnold R. Incidence and prognosis of obstruction of the left ventricular outflow tract in Liverpool (196091): a study of 313 patients. Br Heart J. 1994;71:588-95.

10. Dodge-Khatami A, Schmid M, Rousson V, Fasnacht M, Doell C, Bauersfeld U, et al. Risk factors for reoperation after relief of congenital subaortic stenosis. Eur J Cardiothorac Surg. 2008;33:885-9.

11. Jacobs ML, Chin AJ, Rychik J, Steven JM, Nicolson SC, Norwood WI. Interrupted aortic arch: impact of subaortic stenosis on management and outcome. Circulation. 1995;92(9 Suppl):II128-31.

12. Ruzmetov M, Geiss DM, Shah JJ, Buckley K, Fortuna RS. The Ross-Konno is a high-risk procedure when compared with the Ross operation in children. Ann Thorac Surg. 2013;95:670-5.

13. Valeske K, Huber C, Mueller M, Böning A, Hijjeh N, Schranz D, et al. The dilemma of subaortic stenosis - a single center experience of 15 years with a review of the literature. Thorac Cardiovasc Surg. 2011;59:293-7.

14. Van der Linde D, Roos-Hesselink JW, Rizopoulos D, Heuvelman HJ, Budts W, van Dijk APJ, et al. Surgical outcome of discrete subaortic stenosis in adults: a multicenter study. Circulation. 2013;127:1184-91, e1-4.

15. Kitchiner D, Jackson M, Malaiya N, Walsh K, Peart I, Arnold R, et al. Morphology of left ventricular outflow tract structures in patients with subaortic stenosis and a ventricular septal defect. Br Heart J. 1994;72:251-60.

16. Zielinsky P, Rossi M, Haertel JC, Vitola D, Lucchese FA, Rodrigues R. Subaortic fibrous ridge and ventricular septal defect: role of septal malalignment. Circulation. 1987; 75:1124-9.

17. Smallhorn JF, Anderson RH, Macartney FJ. Morphological characterisation of ventricular septal defects associated with coarctation of aorta by crosssectional echocardiography. Br Heart J. 1983;49:485-94.

18. Barkhordarian R, Wen-Hong D, Li W, Josen M, Henein M, Ho SY. Geometry of the left ventricular outflow tract in fixed subaortic stenosis and intact ventricular septum: an echocardiographic study in children and adults. J Thorac Cardiovasc Surg. 2007; 133:196-203

19. Brown JW, Ruzmetov M, Vijay P, Hoyer MH, Girod D, Rodefeld MD, et al. Operative results and outcomes in children with Shone's anomaly. Ann Thorac Surg. 2005;79:1358-65.

20. St Louis JD, Bannan MM, Lutin WA, Wiles HB. Surgical strategies and outcomes in patients with Shone complex: a retrospective review. Ann Thorac Surg. 2007; 84:1357-62; discussion 1362-3.

21. Delmo Walter EMB, Van Praagh R, Miera O, Hetzer R. Repair of left ventricular inflow tract lesions in Shone's anomaly: valve growth and long-term outcome. Ann Thorac Surg. 2013;95:948-55.

22. Jegatheeswaran A, McCrindle BW, Blackstone EH, Jacobs ML, Lofland GK, Austin EH, et al. Persistent risk of subsequent procedures and mortality in patients after interrupted aortic arch repair: a Congenital Heart Surgeons' Society study. J Thorac Cardiovasc Surg. 2010;140:1059-75.e2.

23. Laksman ZWM, Silversides CK, Sedlak T, Samman AM, Williams WG, Webb GD, et al. Valvular aortic stenosis as a major sequelae in patients with pre-existing subaortic stenosis changing spectrum of outcomes. J Am Coll Cardiol. 2011;58:962-5.

24. Fadel BM, Manlhiot C, Al-Halees Z, Di Salvo G, Al-Ahmadi M, McCrindle B, et al. The fate of the neoaortic valve and root after the modified Ross-Konno procedure. J Thorac Cardiovasc Surg. 2013;145:430-7.e1; discussion 436-7.

25. Maeda K, Rizal RE, Lavrsen M, Malhotra SP, Akram SA, Davies R, et al. Midterm results of the modified Ross/Konno procedure in neonates and infants. Ann Thorac Surg. 2012;94:156-62; discussion 162-3.

26. Leichter DA, Sullivan I, Gersony WM. "Acquired" discrete subvalvular aortic stenosis: natural history and hemodynamics. J Am Coll Cardiol. 1989;14: 1539-44.

27. CCAD collection [Internet]. Available at: http://www.ucl.ac.uk/nicor/audits/ congenitalheartdisease/data. Accessed March 29, 2014 